\title{
O PARCELAMENTO do SOlO ATRAVÉS do loteAmento: O MUNICíPIO E OS LOTEAMENTOS EM SÃO JOSÉ DOS CAMPOS
}

\section{THE DIVISION OF LAND THROUGH ALLOTMENT: THE CITY AND ALLOTMENTS IN SÃO JOSÉ DOS CAMPOS}

\author{
Emmanuel Antonio dos Santos ${ }^{1}$ \\ Arlindo Aparecido Regis de Oliveira Junior ${ }^{2}$
}

Resumo: A questão da terra tem um papel importante no processo da urbanização brasileira. Diante da intensa urbanização das cidades brasileiras nas últimas décadas, o loteamento se apresenta como forma de ocupação do território e alternativa a questão habitacional, porém também se apresenta como problema ao planejamento das cidades. O objetivo do artigo é estudar o parcelamento do solo, na forma de loteamento, como principal estruturador do tecido urbano, conhecendo seus atores, compreendendo as suas lógicas e pertinências, evidenciando ilegalidades nas legalidades apresentadas. O objeto empírico deste estudo é o município de São José dos Campos, localizado na Região Metropolitana do Vale do Paraíba, Estado de São Paulo, a partir de uma abordagem analítica e crítica para uma melhor compreensão desse importante fenômeno urbano.

Palavras-chave: parcelamento do solo; loteamento; segregação socioespacial.

\begin{abstract}
The issue of land has an important role in the process of Brazilian urbanization. During the intense urbanization of the Brazilian cities in the last decades, land subdivision is presented as a form of occupation of the territory and an alternative to the housing issue. However, it also presents a problem for the planning of the cities. The objective of this article is to study land subdivision in the form of allotment, as the main structure of the urban fabric, understand its actors, comprehend its logic and pertinences, and elucidate illegalities within the legalities. The empirical object of this study is the city of São José dos Campos, located in the metropolitan region of the "Vale do Paraiba" (Valley of Paraiba), São Paulo state with a critical and analytical approach for a better understanding of this important urban phenomenon.
\end{abstract}

Keywords: division of land; allotment; socio-spatial segregation.

\footnotetext{
${ }^{1}$ Pós-Doutorado em Ciências Sociais Aplicadas - Università IUAV di Venezia e Docente da Universidade do Vale do Paraíba Univap. E-mail: emmanuel@ita.br.

${ }^{*}$ In memoriam.

${ }^{2}$ Mestrando em Planejamento Urbano e Regional - Univap. E-mail: aregisproj@ig.com.br.
} 


\section{INTRODUÇÃO}

O município de São José dos Campos, cidade localizada a sudeste do Estado de São Paulo, na região do Vale do Paraíba do Sul, objeto deste estudo, é visto como exemplo do acelerado processo de urbanização e expansão vivido pelas cidades médias paulistas.

A cidade se localiza entre os maiores centros urbanos do Brasil, São Paulo e Rio de Janeiro, estrategicamente junto às Rodovias Dutra e Carvalho Pinto, entre as Rodovias Dom Pedro I e Tamoios, que dão acesso à Região Metropolitana de Campinas, e ao litoral norte do Estado de São Paulo.

No artigo, procura-se analisar, especificamente, o Loteamento, seus conceitos, a legislação incidente e as questões que envolvem a terra. No processo de lotear, verificam-se os atores e suas lógicas de trabalho, bem como a influência do loteamento no processo de expansão urbana.

Para a realização desta análise, foram necessários: levantamento de dados de cadastro dos loteamentos junto à Prefeitura Municipal e Cartório de Registro de Imóveis; levantamento de informações históricas e estatísticas, material gráfico e cartográfico, junto ao Arquivo Público Municipal e Prefeitura; mapeamento dos loteamentos na zona urbana do município e geração do mapa que contém a evolução temporal dos loteamentos no período em estudo, de 1930 a 2012.

Mesmo sendo o município de São José dos Campos o objeto empírico desta pesquisa, foram identificados no parcelamento do solo, por meio dos loteamentos, os processos, procedimentos, lógicas e ilegalidades comuns à maioria dos municípios brasileiros.

\subsection{Conceitos e Legislações afins}

A preocupação em se regulamentar o parcelamento do solo tem sua origem na Lei n. 601 de 1850, denominada Lei de Terras. Da promulgação dessa lei até os dias atuais, várias legislações surgiram, podendo-se destacar como principais:

- Decreto Lei n. 58/1937 - institui compra de lotes em parcelas;

- Decreto Lei n. 271/1969 - este decreto, em seu artigo 3oa abre uma brecha na interpretação da legislação, permitindo a possibilidade de se criar condomínios de lotes, embora já questionado por algumas decisões judiciais ${ }^{1}$.

- Lei Federal n. 6766/79 - define exigências técnicas e urbanísticas e considera crime a venda

\footnotetext{
${ }^{1}$ Quando, em terreno onde não houver edificação, o proprietário, o promitente comprador, o cessionário deste ou o promitente cessionário sobre ele desejar erigir mais de uma edificação, observar-se-á também o seguinte:

a) em relação às unidades autônomas que se constituírem em casas térreas ou assobradadas, será discriminada a parte do terreno ocupada pela edificação e também aquele eventualmente reservado como de utilização exclusiva dessas casas, como jardim e quintal, bem assim a fração ideal do todo do terreno e de partes comuns, que corresponderá às unidades.

b) serão discriminadas as partes do terreno que poderão ser utilizadas em comum pelos titulares de direito sobre os vários tipos de unidades autônomas

c) serão discriminadas as áreas que se constituírem em passagem comum para as vias públicas ou para as unidades entre si (BRASIL, 1999).

Art. $3^{\circ}$ - aplica-se aos loteamentos a Lei ํำ4591, de 16 de dezembro de 1964, equiparando-se o loteador ao incorporador, os compradores do lote aos condôminos e as obras de infraestrutura à construção da edificação. (BRASIL, 1967).

Revista Univap - revista.univap.br

São José dos Campos-SP-Brasil, v. 20, n. 35, jul.2014. ISSN 2237-1753
} 
de loteamento sem estar aprovado e registrado, conforme autores.

A regulamentação técnica e jurídica do parcelamento do solo se faz através de legislação urbanística. No universo das leis urbanísticas, a Lei Federal 6.766/79 se destaca primeiro porque é a lei de abrangência nacional que dispõe sobre o parcelamento do solo urbano e, depois, pelo estabelecimento de normas e parâmetros que vieram a nortear e determinar novas posturas nas legislações estaduais e municipais. Além disso, ela é o grande parâmetro urbanístico do país, no que tange à expansão urbana regular após 1980, haja vista que determinou uma série de adequações de leis estaduais e municipais. Isso decorre do fato de que as leis municipais não podem se opor a leis estaduais e federais, respeitadas as respectivas competências definidas pela Constituição Federal. De forma similar as leis estaduais também não podem estar em conflito com leis federais, sendo fundamental sua harmonização, respeitando a abrangência territorial das respectivas competências (BARREIROS; ABIKO, 1998, p. 3).

- Lei Federal n. 9.785, de 29 de janeiro de 1999 - atualiza as exigências da legislação anterior, criando a figura da reserva das áreas públicas relacionadas com a densidade de ocupação do solo.

Após vários anos de regime de exceção, começam aparecer os movimentos sociais, que influencia a Constituição de 1988, na qual a função social da terra passou a ser o elemento fundamental das diretrizes urbanísticas.

No ano de 2001, foi promulgada a lei federal n.10.267, denominada Estatuto da Cidade, contendo instrumentos urbanísticos de intervenção no processo de especulação imobiliária, e o incentivo à participação popular no processo de planejamento urbano, entre outros. Porém, essa lei não é praticada na realidade das cidades brasileiras,

Se em uma primeira leitura o Estatuto da Cidade parece ser um enorme avanço, uma análise mais atenta permite verificar que muitos desses ganhos para a sociedade ainda são de difícil aplicação. Primeiramente, porque o Estatuto da Cidade atrela os novos instrumentos à existência de um Plano Diretor Municipal, o que por um lado é bom, mas por outro faz com que mais uma vez sua regulamentação definitiva sofra o risco de tramitar por uns bons anos nas câmaras municipais. Além disso, muitos dos instrumentos citados, ou mesmo muitas das formulações do texto permitem, no momento de uma regulamentação mais precisa, interpretações variadas. [...] (MARICATO; FERREIRA, 2001, p. 2).

Para um melhor entendimento sobre os termos utilizados, adotam-se os conceitos definidos na legislação de parcelamento do solo mais conhecida - A Lei Federal n. 6.766, de 19 de Dezembro de 1979, que dispõe, em seu artigo $2^{\circ}$, que "o parcelamento do solo poderá ser feito mediante loteamento ou desmembramento, observadas as disposições desta lei e as das legislações estaduais e municipais pertinentes" (BRASIL. Lei n. 6766, 1979) e, também, da autora Holston (1993).

Conforme a Lei Federal n. 6.766,

$\S 1^{0}$ - Considera-se loteamento a subdivisão de gleba em lotes destinados à edificação, com abertura de novas vias de circulação, de logradouros públicos ou prolongamento, modificação ou ampliação das vias existentes. 
$\S 2^{\circ}$ - considera-se desmembramento a subdivisão de gleba em lotes destinados à edificação, com aproveitamento do sistema viário existente, desde que não implique na abertura de novas vias e logradouros públicos, nem no prolongamento, modificação ou ampliação dos já existentes (BRASIL. Lei n. 6766, 1979).

Outros tipos de loteamento são definidos por Holston (1993),

As pessoas compram lotes em quatro tipos de loteamentos, que geralmente aparecem lado a lado na mesma vizinhança: o legal, o irregular, o clandestino, e o grilado. O mais raro dos quatro tipos, o loteamento legal, está de acordo com todas as especificações físicas e burocráticas. O loteamento irregular é - ou melhor, parece ser legitimamente adquirido e registrado por seu empreendedor imobiliário, mas viola, de alguma maneira, as regras de parcelamento da terra. O loteamento clandestino não é registrado no cartório de imóveis, apesar de a terra poder ser de posse legítima de seu empreendedor. Já o loteamento grilado é vendido por um grileiro, que se diz o titular da terra, e o faz através de uma série de artimanhas. A negociata envolvendo a terra, nessa situação, é chamada de grilagem, e a terra, dessa maneira vendida ou adquirida, um grilo. Apesar de o loteamento ilegal frequentemente combinar vários desses aspectos, ele é classificado segundo a sua mais grave infração. Assim, enquanto todos os outros tipos de loteamento estão provavelmente violando os códigos de planejamento urbano, o loteamento grilado enfrenta problemas a mais porque não só é negociado, mas até registrado, na base de documentos fraudados (HOLSTON, 1993, p. 3).

\subsection{Herança colonial patrimonialista}

O princípio que, desde os tempos mais remotos da colonização, norteara a criação da riqueza no país não cessou de valer só um momento para produção agrária. Todos queriam extrair do solo excessivos benefícios sem grandes sacrifícios. Ou, como já dizia o mais antigo de nossos historiadores, queriam servir-se da terra, não com os senhores, mais como usufrutuários, só para desfrutarem e a deixarem destruída (HOLANDA, 2010, p. 52).

Segundo Maricato (1996), parte da população que ocupava áreas mais valorizadas nas principais cidades, no período da República instalada, promoveram reformas urbanas, expulsando a população mais pobre para morar nas periferias das cidades, em áreas impróprias para a ocupação.

A concentração do patrimônio e dos poderes econômicos e políticos constituíram as origens do patrimonialismo, em que os interesses do capital privado se sobrepuseram aos interesses públicos, ou seja, segundo Ferreira (2005), nas cidades como no campo, a estrutura institucional e política de regulamentação do acesso à terra foi sempre implementada no sentido de não alterar a absoluta hegemonia das elites (FERREIRA, 2005, p. 4).

De acordo com a obra de Faoro (2001) o poder sempre esteve concentrado nas mãos de poucos desde a formação social e política do Brasil, e as origens do patrimonialismo caracterizamse, principalmente, pela concentração do patrimônio, do poder econômico e do poder político. Dessa 
forma, a esfera pública sempre foi influenciada pelos interesses do capital privado.

As características marcantes do patrimonialismo, como o clientelismo, o coronelismo e a política da troca de favores, estão presentes até os nossos dias.

Grande parte da população pobre é excluída da cidade consolidada, por meio da implementação de uma legislação que é usada como moeda de troca, e instrumento de dominação, onde a propriedade da terra traz consigo poder político, social e econômico.

Aí reside, talvez, um dos aspectos mais interessantes da lei: aparentemente funciona, como uma espécie de molde da cidade ideal ou desejável. Entretanto, e isto é poderosamente verdadeiro para o caso de São Paulo e provavelmente para a maior parte das cidades latino-americanas, ela determina apenas a menor parte do espaço construído, uma vez que o produto - cidade - não é fruto da aplicação inerte do próprio modelo contido na lei, mas da relação que esta estabelece com as formas concretas de produção imobiliária na cidade. Porém, ao estabelecer formas permitidas e proibidas, acaba por definir territórios dentro e fora da lei, ou seja, configura regiões de plena cidadania limitada. Esse fato tem implicações políticas óbvias, pois, além de demarcar as fronteiras da cidadania, há um importante mecanismo de mídia cultural envolvido, desde que as normas urbanísticas funcionem exatamente como puro modelo. Com isso queremos dizer que, mesmo quando a lei não opera no sentido de determinar a forma da cidade, como é o caso de nossas cidades de maiorias clandestinas, é aí onde ela é mais poderosa no sentido de relacionar diferenças culturais com sistemas hierárquicos (ROLNIK, 1999, pp. 13-14).

Em paralelo, os investimentos ditos sociais, não chegam à população mais pobre, visto que, são utilizadas nas práticas clientelistas entre congressistas, suas bases políticas e empresariais, prefeitos e vereadores, perdendo-se na contratação de obras inacabáveis ou servindo classes mais abastadas.

A consequência mais preocupante é a injustiça social por meio da segregação socioespacial da população pobre, que, não podendo se manter no local onde vive, é expulsa pela elevação de seus custos para sobreviver, sendo obrigada a ocupar espaços cada vez mais distantes, em áreas de risco ou de preservação ambiental, posto que o espaço, como mercadoria preponderante, assume valor de troca e é de suma importância nas possibilidades de acumulação do capitalismo. Entretanto, não se pode afirmar que nem todos os habitantes de uma determinada região são segregados, visto que, muitas vezes, nem todos têm o mesmo padrão socioeconômico. Conforme contribuição de Caldeira (2000), a proximidade espacial entre as classes sociais, com o aparecimento dos condomínios fechados por muros, designados por esse autor como "enclaves fortificados", e o fato de existirem diferentes classes sociais numa mesma região, ou ainda, diferentes interesses de moradores ou do capital, não significa a inexistência ou diminuição da segregação, podendo causar o aumento do acirramento das relações sociais e espaciais entre as diferentes classes. A desigual distribuição espacial dos segmentos sociais é um forte contribuidor do aumento das desigualdades sociais. Dessa forma, a estrutura urbana, representada pelos loteamentos, como consequente utilização da terra urbana, também revela e reproduz as desigualdades sociais, quando se localizam em determinados espaços. 


\subsection{O Município e os Loteamentos em São José Dos Campos}

Baseado nas informações e dados colhidos nesta pesquisa, são realizadas a identificação, a delimitação e a classificação dos loteamentos, conforme se apresenta na Figura 1, mostrando a evolução dos loteamentos no município de São José dos Campos. A seguir, será apresentada uma descrição dos períodos históricos e análises do Município, com a finalidade de uma avaliação do quadro geral do processo de urbanização.
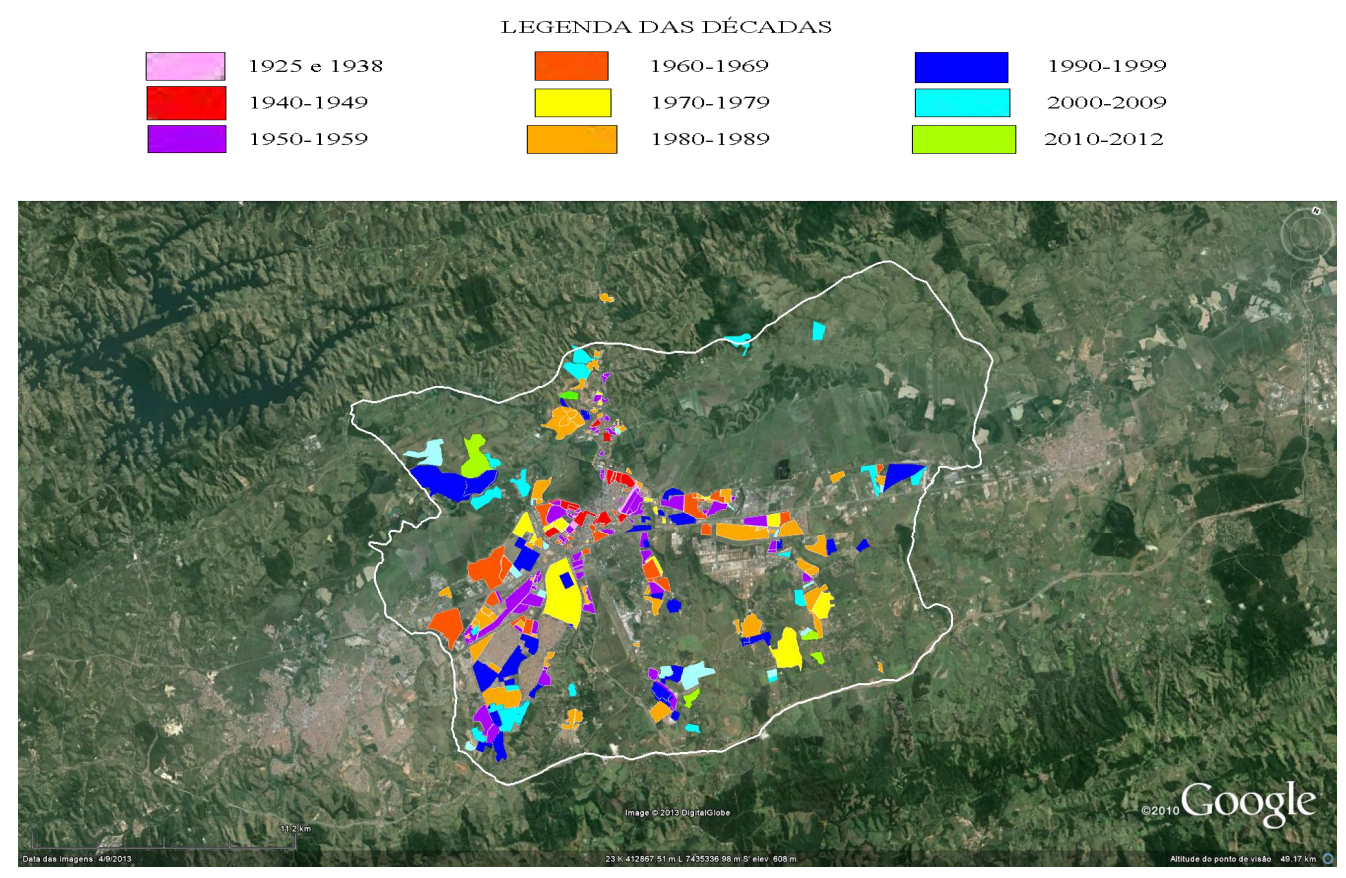

Figura 1 - Mapa Geral da área urbana com a evolução dos loteamentos por décadas. Fonte: Google Maps, e relação de loteamentos fornecida pela Prefeitura Municipal de São José dos Campos, elaborado por Oliveira Junior, 2012.

Até o ano de 1940, foram identificados apenas dois loteamentos oficialmente existentes: Vila Jaci (1925) e Vila Progresso (1938). Por volta de 1930, a legislação de ocupação do solo se restringia à distribuição das atividades, no território, de forma muito genérica, onde o controle da ocupação do espaço era feita voltada às construções.

No ano de 1933, o administrador público, engenheiro Leovigildo Trindade, ordenou que os lotes, na zona central da cidade, deveriam ter área de 1000m2. Os lotes para operários das indústrias teriam área mínima de $300 \mathrm{~m} 2$ e os lotes localizados em zona rural, um mínimo de $1500 \mathrm{~m}^{2}$.

Até o ano de 1932, a cidade era dividida em zonas: comercial, sanatorial e residencial, como se pode observar na Figura 2, sendo que, a partir de 1933, acrescentou-se a zona industrial. 


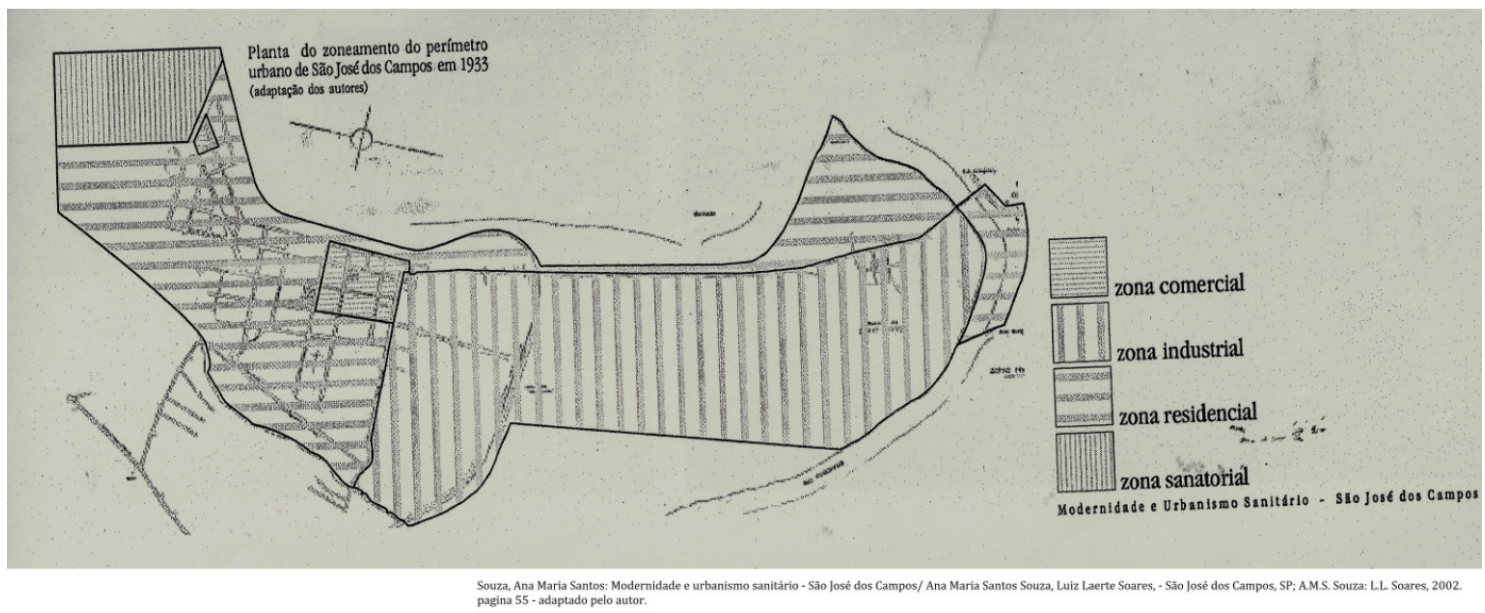

Figura 2 - Mapa de divisão em zonas, São José dos Campos, ano de 1933. Fonte: SOUZA; SOARES, 2002, p. 55.

Segundo Costa (2007), para a zona urbana os lotes deveriam ter grandes dimensões, pois se tratava da visão adotada na Zona Sanatorial de amplos terrenos para proporcionar uma melhor ventilação e insolação, consistindo em uma forma de diferenciação das faixas de renda, promovendo, à época, alguma acessibilidade a terra em condições melhores para os operários.

O mesmo autor afirma que, a partir de junho de 1938, o município passa pelas mais significativas transformações urbanas, com grandes obras urbanísticas, como a construção de uma rede de distribuição de água potável e desapropriação de imóveis, além de novos limites para o perímetro urbano e rural, onde a Zona Sanatorial foi ampliada.

Na Figura 1, entre os anos de 1940 a 1950, observa-se um início do crescimento urbano, onde, de dois loteamentos já existentes, aumenta-se para dez loteamentos, localizados na zona central e um início de dispersão nas áreas mais distantes, porém ainda próximos, fisicamente, uns aos outros.

Conforme constatado, na década de 1950 houve um acelerado processo de crescimento, evidenciado pelo aparecimento de inúmeros loteamentos.

Em comparação com a década anterior, a produção dos loteamentos aumentou em cinco vezes, e segundo os autores,

A inauguração da primeira pista da rodovia Presidente Dutra, em 1950, e sua duplicação, em 1968, implicou maior facilidade de escoamento de mercadorias e o acesso a matérias-primas utilizadas pelas indústrias, atraindo novas instalações e contribuindo para a diversificação da produção industrial, que passa a ocorrer, também, por empresas dos setores de telecomunicação, químico, farmacêutico e automobilístico (SOUZA; COSTA, 2010, p.100). 
Destaca-se, assim, a dinamização da urbanização de São José dos Campos e a necessidade de fluxos e transportes, pois, segundo Costa (2007), a cidade destacou-se pela forte aceleração na taxa de crescimento demográfico e, nas décadas subsequentes, por ser um dos municípios brasileiros com grande crescimento econômico.

A seguir, apresenta-se a Tabela 1, com a porcentagem de crescimento populacional por década; e a Tabela 2, com os números de loteamentos e sua localização geográfica, na cidade, relacionada ao ano de aprovação pela Prefeitura Municipal de São José dos Campos. As tabelas permitem correlacionar os processos de expansão, operando sobre lógicas diferentes, isto é, crescimento populacional com geração de lotes pelo capital.

Tabela 1 - Crescimento Populacional em São José dos Campos

\begin{tabular}{ccc}
\hline Censo & População & $\%$ \\
\hline 1940 & 36.279 & \\
1950 & 44.804 & 23,5 \\
1960 & 77.533 & 73 \\
1970 & 148.332 & 91,3 \\
1980 & 287.513 & 93,8 \\
1990 & 442.370 & 53,9 \\
2000 & 539.313 & 21,9 \\
2010 & 627.544 & 16,4 \\
\hline
\end{tabular}

Fonte: Fundação Sistema Estadual de Análise de Dados (Seade) (2010). Perfil Municipal São José dos Campos. Arquivado do original em 12 de maio de 2012. Página visitada em 6 de maio de 2012. 
Tabela 2 - Loteamentos aprovados em São José dos Campos

\begin{tabular}{|c|c|}
\hline \multicolumn{2}{|c|}{ Décadas de 1940 - 1950} \\
\hline Localização & Quantidade \\
\hline Leste & \\
\hline Oeste & \\
\hline Norte & 4 \\
\hline Sul/Sudeste & \\
\hline Centro & 6 \\
\hline Total & 10 \\
\hline \multicolumn{2}{|c|}{ Décadas de 1950 - 1960} \\
\hline Localização & Quantidade \\
\hline Leste & 10 \\
\hline Oeste & \\
\hline Norte & 12 \\
\hline Sul/Sudeste & 13 \\
\hline Centro & 23 \\
\hline Total & 58 \\
\hline \multicolumn{2}{|c|}{ Décadas de 1960 - 1970} \\
\hline Localização & Quantidade \\
\hline Leste & 2 \\
\hline Oeste & \\
\hline Norte & 3 \\
\hline Sul/Sudeste & 2 \\
\hline Centro & 12 \\
\hline Total & 19 \\
\hline \multicolumn{2}{|c|}{ Décadas de 1970 - 1980} \\
\hline Localização & Quantidade \\
\hline Leste & 8 \\
\hline Oeste & 2 \\
\hline Norte & 3 \\
\hline Sul/Sudeste & 4 \\
\hline Centro & 3 \\
\hline Total & 20 \\
\hline \multicolumn{2}{|c|}{ Décadas de 1980 - 1990} \\
\hline Localização & Quantidade \\
\hline Leste & 15 \\
\hline Oeste & 4 \\
\hline Norte & 13 \\
\hline Sul/Sudeste & 20 \\
\hline Centro & 5 \\
\hline Total & 57 \\
\hline \multicolumn{2}{|c|}{ Décadas de 1990 - 2000} \\
\hline Localização & Quantidade \\
\hline Leste & 9 \\
\hline Oeste & 8 \\
\hline Norte & 3 \\
\hline Sul/Sudeste & 19 \\
\hline Centro & 3 \\
\hline Total & 42 \\
\hline \multicolumn{2}{|c|}{ Período de 2000 - 2012} \\
\hline Localização & Quantidade \\
\hline Leste & 12 \\
\hline Oeste & 7 \\
\hline Norte & 5 \\
\hline Sul/Sudeste & 10 \\
\hline Centro & 2 \\
\hline Total & 36 \\
\hline
\end{tabular}

Fonte: http://www.sjc.sp.gov.br/, elaborado por Oliveira Junior, 2012. 
Pode-se analisar que a maioria dos loteamentos aprovados ficaram próximos ao Centro do município, entre os anos de 1940 a 1970; entre a década de 1970 a 2000, a região leste; e, entre os anos de 2000 até 2012, a região Sul/Sudeste.

Paralelamente a esse fato, identifica-se, nesse período, o início do aparecimento da especulação imobiliária, segundo Souza e Soares (2002), com a alteração da Lei de Zoneamento da cidade,

A desativação de parte da Zona Sanatorial na década de 1950, transformando-a em zona residencial, passou a ser o anseio dos especuladores, ávidos pelos lucros auferidos sobre as transações imobiliárias de uma parte significativa da planície joseense (SOUZA; SOARES, 2002, p. 84).

No ano de 1958, iniciam-se os trabalhos para elaboração do primeiro Plano Diretor de São José dos Campos, por intermédio do CEPEU² da FAUUSP, objetivando criar instrumentos para enfrentar os efeitos negativos de uma forte expansão industrial, bem como, ordenar o uso do solo urbano, limitando as áreas propícias à ocupação por meio dos loteamentos.

Gerou-se, nesse processo, um relatório detalhado sobre o perfil de São José dos Campos, instrumentalizando o poder Público, a partir desse momento, para gerar a legislação específica.

Por fim, nesse ano de 1958 foi elaborado o Código de Edificações de São José dos Campos, moldado na Lei n5261 do Município de São Paulo. Em 1959, foi preparada pelo escritório técnico local e aprovada pela Câmara Municipal uma lei disciplinadora das construções no município. A partir desse momento, deu-se início a elaboração de uma legislação que visava ordenar e resguardar os espaços em razão do crescente impulso industrial, por meio de um novo zoneamento (COSTA, 2007, p. 86).

Isso demonstra o interesse do município em reservar áreas para a indústria e, como consequência, as áreas remanescentes seriam ocupadas pelo residencial misto, obrigando a se rever a legislação do uso e ocupação do solo pela lógica do capital industrial.

Nesse período, pode-se observar a preocupação com a necessidade de moradia popular, visto que o mercado de terras já era voltado para um maior poder aquisitivo oriundo do trabalho industrial.

Dessa forma, em 1951, o prefeito Tertuliano Delfim Junior criou o Departamento da Casa Popular, e posteriormente o Serviço de auxílio à construção Popular, o qual previa a construção de moradias e loteamentos por iniciativa da Prefeitura, com o objetivo de atender a demanda habitacional.

No final da década de 1950 e começo da década de 1960, o planejamento da cidade foi marcado, em função do surgimento, em 1957, da preocupação do governo estadual em regular a

${ }^{2}$ Centro de Pesquisa de Estudos Urbanísticos. 
ocupação urbana nas estâncias hidrominerais, por um lado a indústria da cura e, por outro lado, a regularização da valorização da terra e da distribuição dos recursos do governo à estância.

Quanto à produção dos loteamentos entre 1960 a 1970 houve uma diminuição na quantidade: da produção da década anterior, de cinquenta e oito loteamentos aprovados, diminui-se para dezenove loteamentos.

Os loteamentos irregulares e clandestinos surgem com maior ênfase a partir do final dos anos 70, quando há retração do perímetro urbano e vigência da nova legislação.

Observa-se que a produção dos loteamentos se manteve entre os eixos da Estrada Velha Rio - São Paulo, atualmente Avenida Bacabal e a estrada dos Tamoios, porém acentua-se na direção da Rodovia presidente Dutra, ou seja, pode-se notar que os eixos viários foram relevantes na urbanização de São José dos Campos.

A Rodovia Presidente Dutra foi inaugurada em 1951 e causou grande impacto no município de São José dos Campos, pois os novos loteamentos que surgiram, na década de 50 , não se detiveram nas proximidades do núcleo urbano; atingiram locais distantes, tomando a direção da via Dutra, onde as novas indústrias se instalavam.

Assim criou-se a verdadeira faixa industrializada, intercalada por loteamentos residenciais, sem qualquer infraestrutura. Além disso, muitas vezes invadia áreas produtivas da Zona Rural de maneira esparsa e descontínua (COSTA, 2007, p.86).

Nota-se, nesse período, visivelmente, a segregação socioespacial, no qual se delimitavam as áreas mais privilegiadas para as camadas mais abastadas da população e afastavam o restante da população para áreas mais distantes, fenômeno que ocorre na grande maioria das cidades brasileiras, segundo a autora,

À dificuldade de acesso aos serviços de infraestrutura urbana (transporte precário, saneamento deficiente, drenagem inexistente, difícil acesso aos serviços de saúde, educação, cultura e creches, maior exposição à ocorrência de enchentes e desabamentos) somam-se menores oportunidades de emprego, maior exposição à violência (marginal ou policial), difícil acesso à justiça oficial, difícil acesso ao lazer, discriminação racial. A exclusão é um todo: social, econômica, ambiental, jurídica e cultural (MARICATO, 2003, p. 1).

A partir de 1970, pode-se destacar a elaboração do Segundo Plano Diretor de Desenvolvimento Integrado - PDDI do Município, o incentivo ao processo de verticalização, a criação da CODIVAP e o amplo crescimento econômico da região.

Conforme Costa (2007, p. 93), uma das estratégias adotadas no PDDI foi a de estimular a ocupação e o adensamento de grandes vazios urbanos existentes no município e, por meio dessa diretriz, conseguir certa linearidade na ocupação do solo.

Esse período foi marcado pela regulamentação de diversas leis, como cita Costa (2007),

1. Lei Municipal ํo 1576 de 15 de setembro de 1970 - Dispõe sobre Loteamentos Urbanos; 
2. Lei Municipal ํo 1575 de 25 de setembro de 1970 - Dispõe sobre multas e sanções para todas as obras e edificações que não obedecerem às prescrições do Código de Edificações da Lei de Loteamentos e da legislação sobre uso do solo e zoneamento;

3. Lei Municipal $n \cong 1578$ de 7 de outubro de 1970 - Dispõe sobre o Código de Edificações do Município;

4. Lei Municipal oํ 1606e 1617, respectivamente, de 13 de setembro e 21 de outubro de 1971 - Dispõe sobre o Zoneamento e o Uso do solo;

5. Decreto Municipal no 1412 de 27 de setembro de 1971 - Dispõe sobre a descrição dos perímetros das Zonas de Uso;

6. Lei Municipal no 1623, de 30 de novembro de 1971 - Lei do Plano Diretor (COSTA, 2007, p. 98).

A produção urbana de loteamentos dessa década praticamente se manteve, aumentando de dezenove para vinte loteamentos em comparação à década anterior.

O ano de 1978 foi marcado pelo mandato do prefeito Bevilacqua que criou o projeto de lei que dispunha sobre o parcelamento, uso e ocupação do solo do município.

No ano de 1980, pode-se observar as alterações na lei que privilegiaram o capital imobiliário, como se pode ver em Costa (2007), a lei de zoneamento que foi modificada permitindo atividades antes não autorizadas,

No decorrer dos seus dez anos, a lei 2263/80 sofreu 94 alterações e modificações, sendo que o maior número de alterações ocorreu na gestão do Prefeito Robson Marinho (1983 a 1986) e as alterações mais frequentes visavam prever e respaldar novas situações legais, não previstas ou não permitidas, que pudessem ajustar-se às novas demandas provenientes das mais diversas origens.

As situações mais comuns nessas alterações propostas eram no sentido de a) alterar o zoneamento de uma determinada área ou região a fim de permitir uma determinada atividade outrora não permitida; b) criar novas zonas de uso com parâmetros de uso e ocupação específicos; c) restringir a verticalização em determinados bairros; d) reduzir parâmetros de ocupação do solo e: e) em outros incrementar a taxa de ocupação máxima ou o coeficiente de aproveitamento (COSTA, 2007, p. 167).

Na década de 1980 e 1990, a produção de loteamentos legais retorna em grande número aquecendo a produção de lotes. De vinte loteamentos produzidos na década anterior, surgem cinquenta e sete na década de 1980 e quarenta e dois loteamentos na década de 1990. Já, na década de 2000, estendendo-se até o ano de 2012, houve a produção de trinta e seis loteamentos, produzindo-se, assim, um pouco menos que na década anterior.

Se correlacionado com o crescente crescimento demográfico verificado até os anos 1980, os loteamentos aumentaram na década de 1950, diminuindo nas décadas de 1960 e 1970, como consequência do período conturbado politicamente vividos nesse período, voltando a aumentar na década de 1980. 
Nas décadas seguintes de 1990 e 2000, houve sensível diminuição do crescimento populacional, conforme se pode aferir na Tabela 1. De outro lado, a produção de novos loteamentos, no mesmo período, sofreu pequena diminuição.

Percebe-se, assim, de forma geral, que a expansão urbana em São José dos Campos se caracterizou pela incorporação de áreas de uso agrícola ou rural, para o uso urbano, num estágio inicial e, posteriormente, num estágio mais avançado, no crescimento por adensamento, quando se aumentam a intensidade da verticalização nas áreas já consolidadas.

A forma tradicional legal de incorporação de áreas novas às áreas urbanizadas, em primeiro plano, foi através da alteração do limite urbano por lei municipal e, em segundo, por intermédio da aprovação de um projeto de parcelamento do solo na forma de loteamento, fato este que é comum para muitas cidades.

Para que se obtenha a autorização formal desse procedimento, é necessário se obter a aprovação da Prefeitura Municipal da cidade, para que se possa levar o plano de parcelamento para registro no Cartório e, daí, poder vender os lotes. Os municípios, acompanhando a evolução da técnica e dos costumes ${ }^{3}$, gradativamente foram criando exigências, por meio da legislação de parcelamento e do ordenamento do uso e ocupação do solo, com o argumento do controle de ocupação do espaço urbano. Por outro lado, a preocupação com a forma do crescimento da cidade, por intermédio da emissão das diretrizes emanadas pelo Plano Diretor da Cidade, não tem sido levada em conta, nem no passado, nem no presente. Na obra do autor Villaça (2005), entende-se que planos diretores e leis de zoneamento no Brasil tendem a servir apenas como uma cortina de fumaça tecnicista para esconder as práticas tradicionais e interesses dos grupos dominantes. Contribui, para essa falsa presunção de regulação da ocupação, os novos instrumentos urbanísticos disponibilizados pelo Estatuto das Cidades, mas que nunca são utilizados, bem como, nas audiências públicas, onde haveria a participação e discussão dos temas urbanos, mas que são ardilosamente configurados de forma a inviabilizar a livre manifestação popular.

Desse modo, o município abdica de sua responsabilidade pelo controle do crescimento ordenado da cidade, permitindo que os interesses do capital imobiliário, historicamente sabido, possa gerar o processo denominado de expansão dispersa ou espraiada, tendo como consequência a criação de vazios urbanos, facilitando, assim, a especulação imobiliária, um dos motivos da existência da segregação social, e do aparecimento de centralidades periféricas, longe da área urbana consolidada pela infraestrutura básica, bem como, gerando o aumento do deslocamento da população entre moradia, trabalho e lazer, numa contribuição ao trânsito caótico existentes em nossas cidades.

A produção de novos loteamentos não atende somente a um ou a outro fator distinto, mas sim a vários fatores em conjunto, em que encontramos: o crescimento demográfico, gerando demanda; investimentos privados e públicos, gerando novos postos de trabalho e valorização de setores;

\footnotetext{
${ }^{3}$ Costumes: atos morais tradicionais do homem ou das nações os quais variam segundo os tempos e os lugares (SACOONI, 1996, p. 207).
} 
disponibilidade de glebas; novas concorrências de mercado; alteração constante da legislação, entre outros. A formação de estoque de terras, tendo-a como mercadoria, no modo de produção capitalista, não constitui um fator isolado, mas sim consequência dos demais fatores considerados. Correlacionando a Tabela 1 (crescimento demográfico) com a Tabela 2 (loteamentos aprovados), podemos constatar que o simples crescimento da população não poderá ser utilizado isoladamente como fator gerador da produção imobiliária, visto que nas décadas de 1970 e 1980, houve uma sensível diminuição na produção de loteamentos, se comparado a décadas anteriores.

\subsection{Palco e Atores - O processo de lotear}

Conforme Reis (2006), houve importantes mudanças pós 1980 e 1990, com relação ao esgarçamento crescente do tecido dos principais centros urbanos e, também, em relação aos atores e agentes do setor imobiliário que "se traduz pela atuação e produção concreta, em que viabiliza o acesso a áreas afastadas, pouco densas, alimentado pelo grande capital financeiro, no vigente estágio do capitalismo mundial" (COSTA, 2011).

O ambiente no qual se processa o parcelamento do solo (Loteamento) são as áreas de expansão da urbanização localizadas junto às franjas das cidades, costumeiramente aquelas de valor aquisitivo mais baixo, mesmo que localizadas distantes da área urbanizada, contrariando, assim, uma forma racional de evolução da urbanização, em que a continuidade imediata da expansão da infraestrutura existente seria o mais indicado.

Há, desse modo, uma mudança na apropriação espacial do território pelos mesmos atores, operando com a mesma lógica - acumulação, expropriação, captura - com localização e forma de parcelamento mais atraente para as faixas de mais alta renda.

Por outro lado, os condomínios de alto padrão cada vez mais distantes se fecham em muros e grades, com controle de segurança e acesso, privatizando áreas verdes, institucionais e vias públicas, onde essas comodidades são utilizadas para agregar valor ao preço oferecido da terra, gerando maiores lucros aos empreendedores.

Tal processo de ocupação espacial é o que contribui para a denominada urbanização dispersa, estudada e comentada por Nestor Goulart Reis Filho (2006), bem como, contribui, também, com o processo da criação dos conhecidos Vazios Urbanos, que gera, consequentemente, a especulação imobiliária, processo que tem gerado um círculo vicioso recorrente na produção do espaço urbano, como confirmação do autor Santos (2009),

As cidades são grandes porque há especulação e vice-versa; há especulação porque há vazios e vice-versa; porque há vazios as cidades são grandes. O modelo rodoviário urbano é fator de crescimento disperso e de espraiamento da cidade. Havendo especulação, há criação mercantil da escassez e acentua-se o problema do acesso à terra e à habitação. Mas o déficit de resistências também leva à especulação, e os dois juntos conduzem a periferização da população mais pobre e, de novo, ao aumento do tamanho urbano. As carências em serviços alimentam a especulação, pela valorização diferencial das diversas frações do território urbano.

Revista Univap - revista.univap.br A organização dos transportes obedece a esta logística e torna ainda mais pobres 
os que devem viver longe dos centros, não apenas porque devem pagar caro seus deslocamentos como porque os serviços e bens são mais dispendiosos nas periferias. $\mathrm{E}$ isso fortalece os centros em detrimento das periferias, num verdadeiro círculo vicioso (SANTOS, 2009, p. 106).

De acordo com a pesquisa, reconhecemos que os loteamentos surgem a partir do empresário do ramo que normalmente procura, por intermédio dos corretores de imóveis, áreas ou glebas, de preferência com valores de venda baixos, para aquisição, ou ainda, mais correntemente nas últimas décadas, procura o dono da terra, oferecendo-lhe uma parceria, na qual se constitui em uma sociedade, denominada sociedade de propósito específico (SPE), na qual o proprietário disponibiliza a sua gleba, enquanto o empresário entra com o seu "conhecimento" e com os recursos financeiros necessários à elaboração, aprovação, execução e venda dos lotes resultantes. Assim, ao receber os valores correspondentes às prestações de pagamento dos lotes, estes são rateados, proporcionalmente, entre as partes, de acordo com que foi acertado inicialmente, defendendo seus interesses de lucratividade, como se pode analisar em Oliveira e Pina Filho (2012),

Os objetivos formais do loteador, que seriam criar um espaço adequado para a habitação humana, atendendo as necessidades do mercado alvo e às demandas do mercado imobiliário, geralmente conflitam com seus objetivos reais, que seriam garantir a maior rentabilidade do investimento empregado com a máxima taxa de aproveitamento do terreno e um retorno do capital no menor tempo possível, com rápido início das vendas. Esses objetivos reais do empreendedor podem também conflitar com os objetivos da sociedade, representada pelo poder público e que também detém seus objetivos formais e reais. A harmonia desses interesses deveria então ser promovida pela aplicação da legislação e normas para o parcelamento, mas frequentemente as normas e a aplicação da legislação também são conflitantes (OLIVEIRA; PINA FILHO, 2012, p. 4).

Para a aprovação de um loteamento, é necessário que a gleba considerada esteja situada em zona urbana ou de expansão urbana, definida em lei municipal, conforme determina a legislação em vigor,

Art. $3^{\circ}$ - Somente será admitido o parcelamento do solo para fins urbanos em zonas urbanas, de expansão urbana ou de urbanização específica, assim definidas pelo plano diretor ou aprovadas por lei municipal.

Parágrafo único - Não será permitido o parcelamento do solo:

I - em terrenos alagadiços e sujeitos a inundações, antes de tomadas as providências para assegurar o escoamento das águas;

II - em terrenos que tenham sido aterrados com material nocivo à saúde pública, sem que sejam previamente saneados;

III - em terrenos com declividade igual ou superior a $30 \%$ (trinta por cento), salvo se atendidas exigências especificas das autoridades competentes;

IV - em terrenos onde as condições geológicas não aconselham a edificação;

V - em áreas de preservação ecológica ou naquelas onde a poluição impeça condições sanitárias suportáveis, até a sua correção. BRASIL (Lei n. 6766, 1979).

Muitas vezes essas áreas estão localizadas em zonas rurais, próximas aos limites da zona urbana ou de expansão urbana. Dessa forma, para atender aos interesses do capital imobiliário, o empresário faz seu lobby junto aos agentes públicos, para promoverem a aprovação da passagem 
daquelas áreas, da zona rural para zona urbana ou expansão urbana. Tal prática é recorrente, o que contribui sobremaneira com a incapacidade do agente municipal planejador controlar a ocupação urbana, de forma justa e equilibrada, evitando a conhecida dispersão urbana, em detrimento aos objetivos iniciais da lei de zoneamento, na organização controlada do parcelamento, uso e ocupação do solo urbano.

Como instrumento de organização do crescimento urbano indicado no Plano Diretor da cidade, inicialmente a lei de zoneamento teria como objetivos principais: o controle da urbanização, proteção das áreas inadequadas à ocupação, minimização dos conflitos entre usos e atividades, controle do tráfego, entre outros. Dessa forma, obter-se-ia um controle pelo município, sobre a proporcionalidade entre ocupação e infraestrutura disponíveis, bem como, proteção das áreas frágeis e de interesse cultural. Contudo, seus parâmetros e sua utilização vieram a se transformar em moeda de troca, atendendo aos interesses do capital imobiliário.

Dessa forma, uma vez incluída a área, objeto de interesse do empresário, em zona urbana, este promove os levantamentos e projetos necessários para solicitar a aprovação do empreendimento pretendido - o loteamento, conforme a autora,

A implantação de um loteamento, por exemplo, demanda a obtenção de diretrizes urbanísticas junto ao município; elaboração de planta, memorial descritivo e projeto; contratação de técnicos, dentre engenheiros, arquitetos, geólogos e topógrafos; execução de obras conforme padrões técnicos, incluindo demarcação dos lotes e áreas, abertura de ruas, implantação de rede de distribuição de água, de energia elétrica e de coleta e disposição de esgoto, pavimentação, implantação das galerias de escoamento de águas pluviais, guias e sarjetas; comercialização dos lotes considerando profissionais, marketing e propaganda; recolhimento de impostos; manutenção de elemento de empresa e consequentemente encargos correspondentes, e assim por diante (FADDEN, 2005, pp. 3-4).

Para que se possa colocar à venda os lotes resultantes do parcelamento do solo por meio do loteamento, deverá se ter o projeto de loteamento aprovado e registrado em cartório, devendo, para tanto: solicitar as diretrizes urbanísticas junto à Prefeitura local; elaborar o projeto de acordo com as diretrizes indicadas; promover os laudos e projetos, tanto ambientais como de infraestrutura do loteamento; submetê-los a anuência prévia dos órgãos municipais e de Estado; solicitar a aprovação final junto à Prefeitura Municipal; e realizar o pedido de registro do loteamento junto ao Cartório de Registro de Imóveis local.

Somente após a obtenção do referido registro, é que se pode comercializar os lotes, dando início à execução do empreendimento. Essa execução deverá obedecer ao cronograma de obras apresentado à Prefeitura Municipal quando da aprovação do loteamento.

Apresenta-se como palco desse processo: a gleba e sua localização na cidade.

Na obra de Carlos (2001), na produção do espaço realizada sob a égide da propriedade privada do solo urbano - onde o espaço fragmentado é vendido em pedaços tornando-se intercambiável a partir de operações que se realizam por intermédio e no mercado, tendencialmente produzido enquanto mercadoria - o espaço entra no circuito da troca, generalizando-se na sua 
dimensão de mercadoria. Nesse contexto, o espaço é fragmentado, explorado, e as possibilidades de ocupá-lo se redefine constantemente em função da contradição crescente entre a abundância e escassez, o que explica a emergência de uma nova lógica associada e uma nova forma de dominação do espaço que se reproduz ordenando e direcionando a ocupação a partir da interferência do Estado, aqui entendido, quando a Prefeitura Municipal aprova um novo projeto de Loteamento. Desse modo, o espaço é produzido e reproduzido de um lado enquanto espaço de dominação e de outro enquanto mercadoria reprodutível.

Nesse contexto, o uso do espaço na cidade subordina-se, cada vez mais, à troca, à reprodução do valor de troca que submete o uso às necessidades do mercado imobiliário.

Como atores dessa reprodução, podem-se destacar: o dono da gleba; o intermediário (corretor de imóveis); o empresário do setor imobiliário (construtor e/ou loteador); o profissional projetista do loteamento; os funcionários públicos envolvidos na análise e aprovação dos projetos; o Prefeito e seus assessores; e, como coadjuvantes - os vereadores. Mais recentemente, identificamos outro ator atuante nesse processo - as entidades profissionais e corporativas.

Conforme Abramo (2007), pode-se identificar as novas formas de atuação sobre a mercadoria "cidade", mercadoria que é vendida aos pedaços. Criando desejos e falsas desvalorizações/valorizações e criando sua própria demanda por intermédio do desejo.

As associações de profissionais ligados à arquitetura e engenharia, com interesses comerciais diretamente relacionados com os projetos e serviços técnicos que esses empreendimentos geram, têm apoiado o capital imobiliário, manifestando-se perante os órgãos da gestão municipal no sentido de solicitar a flexibilização das exigências constantes da legislação urbanística e construtiva, especificamente a de parcelamento do solo, para benefício de seus clientes - o capital imobiliário, posto que a cidade é tanto o palco quanto o objeto das formas de acumulação por meio do uso e ocupação privilegiado da política.

Já as associações corporativas, que reúnem os empresários do setor, defendem a flexibilização das exigências e normas de uso, parcelamento e ocupação do solo, além daquelas construtivas, para que permitam, cada vez mais, o máximo de aproveitamento das terras em lotes, ou das construções em número de unidades, de modo a retirar o maior lucro possível, partindo das características atribuídas à terra, baseado no autor,

A terra como um ativo apresenta três características importantes: a) é escassa, só existe em quantias fixas e não pode ser facilmente criada; b) não é móvel; e c) é durável, já que não pode ser destruída facilmente. Essas características fazem da terra um ativo atraente como fator produtivo, como garantia para o crédito e como reserva de valor.

A terra, além de possuir características gerais de um ativo, ainda conta com as seguintes condições específicas: a) tem um mercado secundário constituído; e b) é economicamente escassa. Assim, tanto a geração de tecnologia para a elevação do seu rendimento físico quanto medidas administrativas, por exemplo, regulação efetiva dos mercados de terras, podem alterar o grau de escassez da terra (REYDON, 2007, p. 28). 


\section{CONCLUSÃO E PERSPECTIVAS}

De todos os atores identificados no "palco" dos problemas urbanísticos, o que certamente os integram é a manutenção do capital privado por meio da apropriação desigual das oportunidades de uso e ocupação do solo. Não é de se estranhar que, no rol dos maiores contribuidores das campanhas políticas para prefeito e vereadores, estão as construtoras/incorporadoras e loteadoras.

No passado, o empresário do ramo imobiliário se apresentava como Construtor ou Loteador e, junto às suas associações de classe, defendia, legitimamente, os seus interesses.

Nas últimas décadas, observa-se não só no processo de planejamento urbano municipal, mas também na postura pública dos gestores públicos e empresários do setor imobiliário, a utilização do "discurso" da solução dos problemas sociais que utilizam os jargões: solucionar a falta de habitação popular, geração de mais empregos, ou ainda, sustentabilidade e ecologia, como justificativa às suas ações para camuflar os seus reais objetivos, como podemos depreender na pesquisa. Tanto é notável, que grande parte das empresas do setor imobiliário não utilizam mais a razão social de Loteadoras, mas sim, empresas de desenvolvimento urbano ou de urbanismo, designação mais alinhada com o discurso difundido.

Embora se deva reconhecer que o capital imobiliário tenha papel importante na construção do espaço urbano, o principal ator identificado seria a administração municipal, o qual poderia controlar e equilibrar os interesses representativos dos vários setores da sociedade, e também da população social e espacialmente excluída.

Por outro lado, profissionais que ocupam função de decisão na administração pública com vontade de mudar essa práxis, vêm-se em situação de relativo engessamento ou sob o risco de serem tentados a aderirem à lógica do clientelismo, aqui entendido como a forma de facilitar as autorizações municipais em troca de benefícios de ordem pessoal.

A legislação urbanística e seus instrumentos de intervenção existentes são suficientes para esse trabalho. Todavia, os interesses privados e não coletivos, frutos de uma herança patrimonialista, impedem o progresso da solução dos problemas urbanos.

Observa-se, nesse processo, a ausência de um ator importante que poderia contribuir e influenciar, positivamente, na solução dos problemas urbanísticos - a academia. Na região de São José dos Campos, existem várias universidades e institutos de qualidade, os quais detêm o conhecimento necessário, de método, análise e diagnóstico das questões socioespaciais, o que poderia contribuir, e muito, com o planejamento urbano municipal. Todavia estas são "deixadas de lado" das oportunidades formais de contribuição e intervenção.

Confirmando o que é apresentado na obra de Faoro (2001), tudo acontece porque o Estado, como intermediador dos conflitos, entendido aqui como regulador entre os interesses privados e os coletivos, embora ele possua uma aura de neutralidade, isto é, embora ele se apresente como neutro, na prática, ele tende à manutenção dos interesses privados. Os interesses políticos representam o interesse de uma determinada classe e não da coletividade, e nem sempre operam

uma lógica transparente nas ações tomadas pelo poder, principalmente as barganhas realizadas, em que se ganha o interesse privado, em detrimento ao interesse coletivo. 


\section{REFERÊNCIAS}

ABRAMO, P. A cidade caleidoscópica: coordenação espacial e convenção urbana: uma perspectiva heterodoxa para a economia urbana. Rio de Janeiro: Bertrand Brasil, 2007.

BARREIROS, M.; ABIKO, A. K. Reflexões sobre o parcelamento do solo urbano. São Paulo: Escola Politécnica, 1998 (Boletim Técnico do PCC).

BRASIL. Decreto-lei no 58, de 10 de dezembro de 1937. Dispõe sobre o loteamento e a venda de terrenos para pagamento em prestações. Disponível em: <http://www.planalto.gov.br/ccivil 03/decreto-lei/1937-1946/Del058.htm>. Acesso em: 12 jul. 2013. - Lei Federal n. 601, de 18 de setembro 1850. Lei de Terras. Disponível em: <http://www.planalto.gov.br/ccivil 03/Leis/L0601-1850.htm>. Acesso em: 12 jul. 2013.

. Lei n. 10.257 de 10 de julho de 2001. Regulamenta os arts. 182 e 183 da Constituição Federal, estabelece diretrizes gerais da política urbana e dá outras providências. Brasília, DF: Diário Oficial, 2001.

. Lei n. 6.766, de 19 de dezembro de 1979. Dispõe sobre o Parcelamento do Solo Urbano e dá outras Providências. Presidência da República, Casa Civil, Brasília, 1979. Disponível em: <http://www.planalto.gov.br/ccivil/LEIS/L6766.htm>. Acesso em: 2 jul. 2013.

CARLOS, A. F. A. São Paulo hoje: As contradições no processo de Reprodução do Espaço. Scripta Nova Revista Electronica de Geografia Y Ciencias Sociales, Barcelona, n. 88, 1 de mayo de 2001. Disponível em: <http://www.ub.es/geocrit/sn/sn-146(046).htm>. Acesso em: 2 jul. 2013.

COSTA, P. E. O. Legislação urbanística e crescimento urbano em São José dos Campos. 2007. 257 f. Dissertação (Mestrado) Faculdade de Arquitetura e Urbanismo, Universidade de São Paulo, São Paulo, 2007.

COSTA, M. L. P. M. Dispersão urbana: As questões e a busca de seus equacionamentos. Resenhas online. Vitruvius, 2011.2 Disponível em: <http://www.vitruvius.com.br/revistas/read/resenhasonline/09.108/3833>. Acesso em: 7 nov. 2013.

FADDEN, S. M. Parcelamentos Ilegais do Solo: Aspectos Urbanísticos e Regularização. 2005. Monografia (Graduação em Direito). Universidade Metodista de Piracicaba, Piracicaba, 2005.

FAORO, R. Os donos do poder: formação do patronato político brasileiro. 3. ed. rev. São Paulo: Globo, 2001.

FERREIRA, J. S. W. A cidade para poucos: breve história da propriedade urbana no Brasil. In: SIMPÓSIO INTERNACIONAL: Interfaces das Representações Urbanas em Tempos de Globalização, 2005, Bauru. Anais... Bauru, SP: FAU Unesp Bauru; SESC Bauru, 2005. CD Rom.

HOLANDA, S. B. Raízes do Brasil. 4. ed. revista pelo autor. São Paulo: Companhia das Letras, 2010.

HOLSTON, J. Legalizando o ilegal: propriedade e usurpação no Brasil. Revista Brasileira de Ciências Sociais, v. 8, n. 21, pp. 68-98, fev. 1993. 
MARICATO, E.; FERREIRA, J. S. W. Estatuto da Cidade: essa lei vai pegar? Correio da Cidadania, São Paulo, $\quad$ n. 252, jul. 2001.2 Disponível em: <http://www.correiocidadania.com.br/antigo/ed252/politica.htm>. Acesso em: 2 jul. 2013.

MARICATO, E. Conhecer para resolver a cidade ilegal, 2003. Disponível em: $<$ http://www.usp.br/fau/depprojeto/labhab/biblioteca/textos/maricato conhecercidadeilegal.pdf>. Acesso em: 12 jul. 2013.

. Metrópole na periferia do capitalismo: desigualdade, ilegalidade e violência. São Paulo: Hucitec, 1996.

OLIVEIRA, M. L. de; PINA FILHO, A. C. Parcelamento do solo urbano: uma abordagem sistêmica. Chão urbano, Rio de Janeiro, v. 12, n. 3, maio/jun. 2012. Disponível em: $<$ http://www.chaourbano.com.br/adm/revistas/arquivos/revista79.pdf >. Acesso em: jul. 2013.

REIS FILHO, N. G. Notas sobre Urbanização Dispersa e Novas Formas de Tecido Urbano. São Paulo: Via das Artes, 2006. 201p.

REYDON, B. P. A regulação institucional da propriedade da terra no Brasil: uma necessidade urgente. In: RAMOS, P. et. al. (coord.). Dimensões do agronegócio brasileiro: políticas instituições e perspectivas. Brasília: MDA, 2007.

ROLNIK, R. A cidade e a lei: Legislação, política urbana e territórios na cidade de São Paulo. São Paulo, SP: Studio Nobel, FAPESP, 1997. 242p.

SACCONI, L. A. Gramática Para Todos Os Cursos e Concursos Sacconi - Teoria e Prática - 5. ed. São Paulo: Nova Esperança, 2013, 1996, p. 207.

SANTOS, M. Espaço e método. São Paulo: Nobel, 2009.

SOUZA, A. A. M.; COSTA, W. M. Atividades industriais no interior do estado de São Paulo: uma análise da formação do complexo tecnológico - industrial - aeroespacial de São José dos Campos. In: FONSECA, S. M.; MELLO, L. F. (Orgs.) Crescimento Urbano e industrialização em São José dos Campos. São José dos Campos: Intergraf, 2010.

SOUZA, A. M. S.; SOARES, L. L. Modernidade e Urbanismo Sanitários São Jose dos Campos. São Jose dos Campos, SP: 2002.

VILLAÇA, F. As llusões do Plano Diretor, 2005. Disponível em: <http://www.planosdiretores.com.br/downloads/ilusaopd.pdf>. Acesso em: 17 set. 2013. 